\title{
Comparison of vaginal hysterectomy and laparoscopic hysterectomy: a systematic review and meta-analysis
}

Seung Hyun Lee ${ }^{1 \dagger}$, So Ra Oh${ }^{1 \dagger}$, Yeon Jean Cho', Myoungseok Han'ㄹ, Jung-Woo Park', Su Jin Kim', Jeong Hye Yun', Sun Yi Choe ${ }^{1}$, Joong Sub Choi ${ }^{2}$ and Jong Woon Bae ${ }^{1 *}$ (D)

\begin{abstract}
Background: There are various surgical approaches of hysterectomy for benign indications. This study aimed to compare vaginal hysterectomy $(\mathrm{VH})$ and laparoscopic hysterectomy $(\mathrm{LH})$ with respect to their complications and operative outcomes.

Methods: We selected randomised controlled trials that compared VH with LH for benign gynaecological indications. We included studies published after January 2000 in the following databases: Medline, EMBASE, and CENTRAL (The Cochrane Library). The primary outcome was comparison of the complication rate. The secondary outcomes were comparisons of operating time, blood loss, intraoperative conversion, postoperative pain, length of hospital stay and duration of recuperation. We used Review Manager 5.3 software to perform the meta-analysis.

Results: Eighteen studies of 1618 patients met the inclusion criteria. The meta-analysis showed no differences in overall complications, intraoperative conversion, postoperative pain on the day of surgery and at $48 \mathrm{~h}$, length of hospital stay and recuperation time between $\mathrm{VH}$ and $\mathrm{LH}$. VH was associated with a shorter operating time and lower postoperative pain at $24 \mathrm{~h}$ than $\mathrm{LH}$.
\end{abstract}

Conclusions: When both surgical approaches are feasible, VH should remain the surgery of choice for benign hysterectomy.

Keywords: Laparoscopic hysterectomy, Vaginal hysterectomy, Meta-analysis

\section{Backgrounds}

A substantial number of women undergo hysterectomy annually, and $70 \%$ of hysterectomies are performed for benign indications, including leiomyoma, adenomyosis, severe dysmenorrhea and uterine prolapse [1]. The surgical approach of hysterectomy is the most important factor responsible for postoperative morbidity. Until the present, the approaches for hysterectomies are vaginal, abdominal, laparoscopic and robotic assisted laparoscopic hysterectomy. If feasible, vaginal hysterectomy is associated with a shorter duration of hospital stay, speedier recuperation, fewer unspecified infections or febrile episodes than

\footnotetext{
* Correspondence: jwbae@dau.ac.kr

†'Seung Hyun Lee and So Ra Oh are first authors.

${ }^{1}$ Department of Obstetrics and Gynaecology, College of Medicine, Dong-A University, Busan, 26 Daesingongwon-Ro Seo-Gu, Busan 602-812, Republic of Korea

Full list of author information is available at the end of the article
}

abdominal hysterectomy [2]. Since Reich first performed laparoscopic hysterectomy (LH) in 1989, various laparoscopic techniques and instruments have been developed, resulting in the vigorous implementation of $\mathrm{LH}$, including laparoscopic-assisted vaginal hysterectomy (LAVH) and total laparoscopic hysterectomy (TLH) at present [3]. In contrast, $\mathrm{VH}$ is commonly utilized to treat uterine prolapse, but despite proven safety and effectiveness, it remains underutilized for the surgical treatment of nonprolapse conditions [4]. Gynaecologists perform LAVH or TLH according to their preference, and it is conservative to say that gynaecologists performing LH almost never perform VH [4]. There are several reasons for the widespread implementation of LH. First, LH can facilitate a better anatomical view, which has advantages over $\mathrm{VH}$ in cases of severe endometriosis or when there is a history of pelvic inflammatory disease. Second, in cases of large

(C) The Author(s). 2019 Open Access This article is distributed under the terms of the Creative Commons Attribution 4.0 International License (http://creativecommons.org/licenses/by/4.0/), which permits unrestricted use, distribution, and 
uterine size and for uteruses with little or no descent, LH simplifies the separation of the uterus from its attachment to the pelvic wall [5]. There are multiple approaches to hysterectomy, and each method has its procedure-specific advantages and disadvantages. Since VH and LH are minimally invasive techniques for benign indications that are widely performed around the world, we present a meta-analysis of randomised controlled trials (RCTs) comparing LH with $\mathrm{VH}$ for benign gynaecological conditions to identify which surgical approach is superior with respect to various surgical outcomes, especially the rates of complications.

\section{Methods}

\section{Criteria for considering studies for this review}

We selected RCTs that compared VH with LH (LAVH or TLH or unspecified LH) published from January 2000. No language restriction was used. We included women who underwent $\mathrm{VH}$ and $\mathrm{LH}$ for benign gynaecological indications and excluded women with gynaecological malignancies.

\section{Study outcomes}

The primary outcome of the present analysis was the incidence of intraoperative and postoperative complications. Operative complications were classified by the Dindo classification of surgical complications [6]. Secondary outcomes were operating time, blood loss, rate of conversion to laparotomy, postoperative pain, length of hospital stay and length of recuperation.

\section{Search methods for studies: electronic searches}

This meta-analysis was prepared in accordance with the recommendations of the Preferred Reporting Items for Systematic Reviews and Meta-Analyses Statement (PRISMA Statement) [7, 8]. A literature search for articles published from 1 January 2000 to present was conducted within the main international databases. We searched records from the following databases: Medline, EMBASE, and CENTRAL (The Cochrane Library) for combinations of the terms "hysterectomy," "laparoscop", " "vagina"," "laparoscop"” AND assisted AND vagina", "and" "benign AND condition"" OR indication* OR disease" OR "disorder". Symbol "was used for truncation.

\section{Data collection and analysis}

The studies were included after fulfilling the following inclusion criteria: RCTs; hysterectomy performed for benign gynaecological conditions, and $\mathrm{VH}$ outcomes compared with those of any LH. Studies were excluded from the analysis if any one of the inclusion criteria was not met. Two reviewers (SR Oh and SH Lee) independently reviewed the articles and extracted the data. Disagreements were resolved by the other reviewers (JH Yoon,
SE Choi). Two reviewers (SR Oh and SH Lee) worked independently and examined the potential eligibility of all the studies retrieved from the database after fulfilling the inclusion and exclusion criteria. Next, they extracted and assessed the risk of bias in each full text article. The other reviewers (JH Yoon, SE Choi) resolved inconsistencies between the first two reviewers through consensus of the whole research team.

\section{Data extraction and management}

First reviewers extracted data from the included studies. The data was confirmed twice by the second reviewers to minimize potential errors. Conflicts were resolved by consensus and discussion. The data extracted from each study included the author, publication year, type of study, number of patients, routes of hysterectomy $(\mathrm{VH}$, LAVH, TLH and unspecified LH), and outcomes (complications, operating time, blood loss, intraoperative conversion, postoperative pain, length of hospital stay and length of recuperation). We first tried to extract numerical data from tables, text or figures. If these data were not reported numerically, we extracted data from graphs using digital ruler software. When summary data included only the median and range, data were transformed according to the methods described by Hozo et al. [9].

\section{Risk of bias assessment and data analysis}

We used tools for assessing quality and risk of bias from the Cochrane Handbook for Systematic Reviews of Interventions to evaluate the methodological quality of RCTs [10]. The following seven items were evaluated:

(1) Random sequence generation

(2) Allocation concealment

(3) Blinding of participants and personnel

(4) Blinding of outcome assessment

(5) Incomplete outcome data

(6) Selective reporting

(7) Other bias

The answers for each item included "low" (low risk of bias), "unclear" (either lack of information or uncertainty over the potential for bias), or "high" (high risk of bias). Pairs of independent reviewers assessed the methodological quality. Discrepancies were resolved by consensus of the whole team. A meta-analysis was conducted using Review Manager version 5.3 software, which was designed for and used in Cochrane reviews. Random-effects models were used to calculate a pooled estimate of effect in the metaanalysis. The dichotomous outcomes of each study are represented as the risk ratio (RR) with an estimated 95\% confidence interval $(\mathrm{CI})$. The continuous variables are shown as the weighted mean difference (WMD) with 95\% CI, which were calculated from the mean, standard deviation (SD), $p$ - 
value, and sample size of each study. Heterogeneity was assessed using Higgins $\mathrm{I}^{2}$ value that evaluates the percentage of total variation across a study due to heterogeneity rather than by chance alone: low heterogeneity $\left(\mathrm{I}^{2}<25 \%\right)$, moderate heterogeneity $\left(\mathrm{I}^{2}=25\right.$ to $\left.75 \%\right)$, and high heterogeneity $\left(\mathrm{I}^{2}>75 \%\right)$. We used GRADEpro GTD web-based software to rate the quality of each outcome according to GRADE guidelines [11-13].

\section{Results}

The primary search retrieved 1611 citations with combinations of the terms "hysterectomy", "laparoscop", "vagina"", "laparoscop" AND assisted AND vagina*" and "benign AND condition* OR indication* OR disease* OR disorder"", which were screened for eligible studies. After excluding duplicate citations, 1041 potentially eligible citations were identified and examined in detail. Of these, 1023 articles were excluded because of the inclusion of only one surgical approach (VH or TLH or LAVH), non-RCT design or inclusion of patients with malignancies. Eighteen articles reporting results from RCTs comparing VH $(n=677)$ with LH $(n=941)$ were included in the present meta-analysis (Fig. 1). The meta- analysis was performed using Review Manager, and the studies comparing $\mathrm{VH}$ and $\mathrm{LH}$ were divided into three subgroups: VH vs. LAVH; VH vs. TLH; and VH vs. unspecified LH. Hence, the number of studies on VH was duplicated in each outcome. The risks of bias in the included studies are summarised in Fig. 2.

\section{Inclusion/exclusion criteria of studies}

Table 1 details the inclusion and exclusion criteria for the 18 studies included in this meta-analysis. Two of the studies specified inclusion of hysterectomy for benign uterine diseases only, and 12 studies included benign uterine diseases and limit of uterine or myoma size. Three studies included benign uterine diseases and possible $\mathrm{VH}$. One included myoma size larger than $8 \mathrm{~cm}$. Four of the included trials excluded women with pelvic organ prolapse (POP) beyond stage I, and eight studies excluded women with pelvic inflammatory disease, endometriosis and/or previous uterine surgeries.

\section{Primary outcome}

Seventeen trials reported incidences of perioperative complications [5, 14-29], which were classified by Dindo

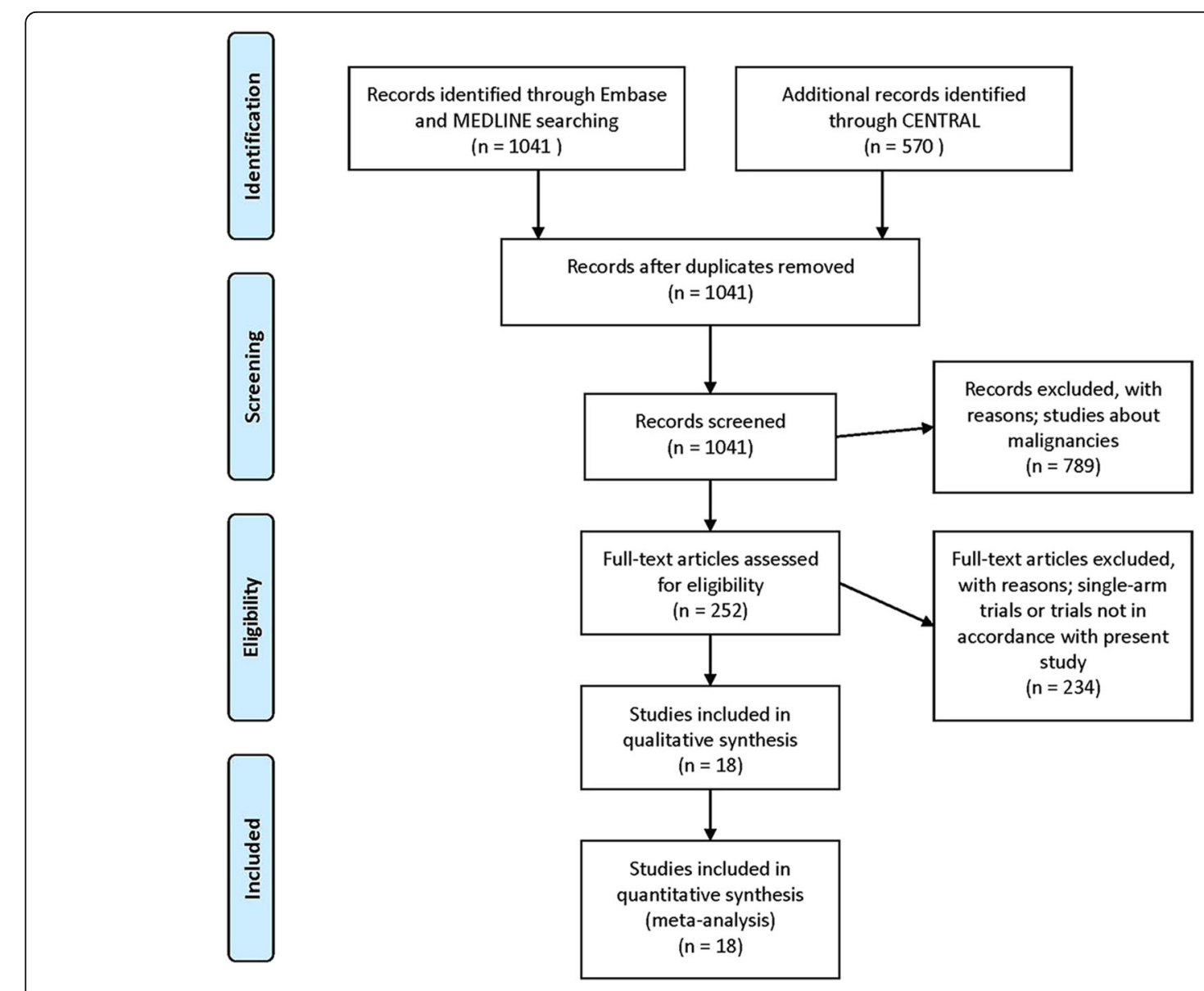

Fig. 1 PRISMA flow diagram of the study screening and selection process 


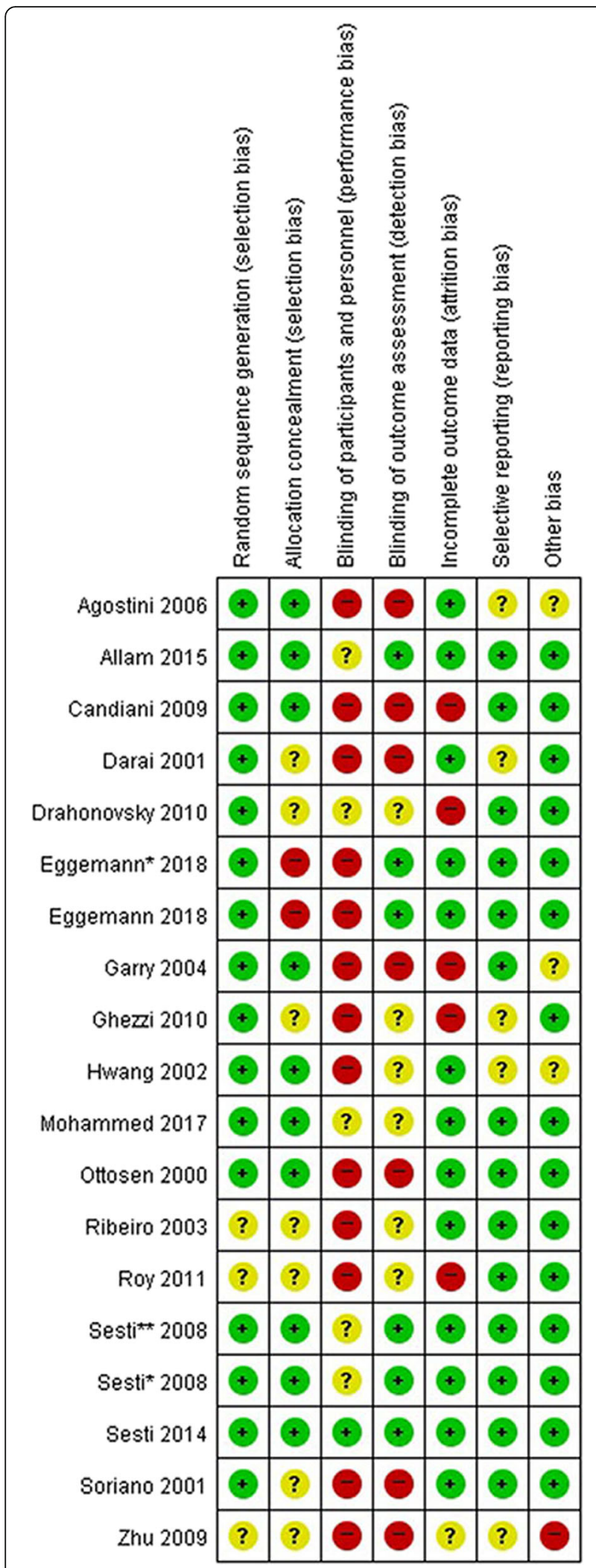

Fig. 2 Risk of bias summary. Green circle (low risk), yellow circle (unclear), red circle (high risk) classification (grade I to V) [6]. No difference in the rate of overall complications was found between $\mathrm{VH}$ and $\mathrm{LH}$ (RR $1.11,95 \% \mathrm{CI} ; 0.85$ to $1.45, p=0.46$ ). There was also low heterogeneity $\left(\mathrm{I}^{2}=25 \%\right.$ ) (Fig. 3). Table 2 summarises all the complications in the included studies. Grade I complications were fever, vault hoematoma, urinary tract infection, vaginal bleeding, urinary retention and unspecified infections. No significant differences in the incidence of grade I complications were demonstrated between VH and LH (RR 1.20, 95\% CI; 0.90 to 1.61, $p=$ 0.22 ), and there was low heterogeneity $\left(\mathrm{I}^{2}=19 \%\right.$ ) (Fig. 3) . Most of the grade II complications was transfusion $(n=82)$. One patient in the VH group was treated with heparin because of deep vein thrombosis and experienced a spontaneous resolution. No significant difference in the incidence of grade II complications was demonstrated between $\mathrm{VH}$ and $\mathrm{LH}$ (RR 0.78, 95\% CI; 0.49 to $1.24, p=0.30$ ), and there was low heterogeneity $\left(\mathrm{I}^{2}=0 \%\right)$ (Fig. 4). Grade III complications included those requiring surgical, endoscopic, or radiological intervention. There was one ureteral injury, seven bladder injuries and two reoperations in the $\mathrm{VH}$ group and eight bladder injuries, one vesicovaginal fistula, one ureterovaginal fistula, one reoperation and two pulmonary embolisms in the LH group. No significant difference in the incidence of grade III complications was demonstrated between VH and LH (RR 1.03, 95\% CI; 0.49 to 2.16, $p=$ $0.94)$, and there was low heterogeneity $\left(\mathrm{I}^{2}=0 \%\right)$ (Fig. 4$)$. No significant difference in the incidence of urinary tract injury was demonstrated between VH and LH (RR 1.19, 95\% CI; 0.52 to $2.71, p=0.68)$, and there was low heterogeneity $\left(\mathrm{I}^{2}=0 \%\right)$. None of the trials included in the present analysis reported any grade IV or V complications after either $\mathrm{VH}$ or $\mathrm{LH}$.

\section{Secondary outcomes}

Secondary outcomes were operating time, blood loss, intraoperative conversion, postoperative pain, length of hospital stay and length of recuperation. Eighteen studies reported on operating time [5, 14-18, 20-31]. VH was associated with a shorter operating time than $\mathrm{LH}$ (WMD $-34.01 \mathrm{~min}$, 95\% CI; -43.54 to $-24.48 \mathrm{~min}$, $p<.0001$ ) (Fig. 5), and there was high heterogeneity between the trials $\left(\mathrm{I}^{2}=98 \%\right)$. However, all studies except one favored VH [31]; thus, the risk of inconsistency for this outcome was not severe. There was no difference in blood loss between VH and LH (WMD - $35.91 \mathrm{~mL}$, 95\% $\mathrm{CI} ;-102.26$ to $30.43 \mathrm{~mL}, p=0.29)$ in 12 studies $[5,14$, $17,21-29]$. There was high heterogeneity $\left(\mathrm{I}^{2}=97 \%\right)$ between trials. Twelve studies assessed intraoperative conversion [14, 17-19, 21, 23-29]. No difference was found between VH and LH (RR 1.16, 95\% CI; 0.60 to 2.26, $p=$ $0.66)$, and there was low heterogeneity $\left(\mathrm{I}^{2}=0 \%\right)$. Postoperative pain scores were evaluated using the visual 
Table 1 Characteristics of included studies

\begin{tabular}{|c|c|c|c|c|c|c|c|}
\hline $\begin{array}{l}\text { First author, } \\
\text { year }\end{array}$ & $\begin{array}{l}\text { Type } \\
\text { of } \\
\text { study }\end{array}$ & Method & $\begin{array}{l}\text { Number } \\
\text { of } \\
\text { patients }\end{array}$ & Inclusion criteria & Exclusion criteria & Outcomes & $\begin{array}{l}\text { Risk of bias } \\
\text { according to } \\
\text { Cochrane risk of } \\
\text { bias tools }\end{array}$ \\
\hline $\begin{array}{l}\text { Agostini, } \\
2006\end{array}$ & RCT & LAVH vs. VH & 48 & $\begin{array}{l}\text { Benign uterine diseases, } \\
\text { uterine size below pubis, } \\
\text { favorable to } \mathrm{BSO}^{\dagger}\end{array}$ & Adnexal mass & $\begin{array}{l}\text { Operative data, } \\
\text { complications }\end{array}$ & high \\
\hline Allam, 2015 & RCT & $\begin{array}{l}\text { TAH vs.TLH } \\
\text { vs. VH }\end{array}$ & 60 & Benign uterine diseases & Malignancy & $\begin{array}{l}\text { Operative data, } \\
\text { complications }\end{array}$ & unclear \\
\hline $\begin{array}{l}\text { Candiani, } \\
2009\end{array}$ & RCT & TLH vs. VH & 47 & Benign uterine diseases & $\begin{array}{l}\text { Malignancy, estimated uterine } \\
\text { volume }>300 \mathrm{~mL} \text {, POP }{ }^{\ddagger} \text {, ovarian } \\
\text { pathology, PID } \text { endometriosis }^{\text {end }}\end{array}$ & $\begin{array}{l}\text { Operative data, } \\
\text { complications }\end{array}$ & high \\
\hline Darai, 2001 & RCT & LAVH vs. VH & 80 & $\begin{array}{l}\text { Estimated uterine size > } \\
280 \mathrm{~g} \text {, contraindications } \\
\text { to } \mathrm{VH}\end{array}$ & Malignancy & $\begin{array}{l}\text { Operative data, } \\
\text { complications }\end{array}$ & high \\
\hline $\begin{array}{l}\text { Drahonovsky, } \\
2010\end{array}$ & $\mathrm{RCT}$ & $\begin{array}{l}\text { LAVH vs. } \\
\text { TLH vs. VH }\end{array}$ & 125 & Benign uterine diseases & $\begin{array}{l}\text { Impossible VH, prior abdominal } \\
\text { surgery, endometriosis, medical } \\
\text { disorders }\end{array}$ & $\begin{array}{l}\text { Operative data, } \\
\text { complications }\end{array}$ & high \\
\hline $\begin{array}{l}\text { Eggemann, } \\
2018\end{array}$ & RCT & LAVH vs. VH & 192 & $\begin{array}{l}\text { Benign uterine diseases, } \\
\text { possible VH }\end{array}$ & $\begin{array}{l}\text { Malignancy, POP }{ }^{\ddagger} \text {, medical } \\
\text { disorders }\end{array}$ & $\begin{array}{l}\text { Operative data, } \\
\text { complications }\end{array}$ & high \\
\hline Garry, 2014 & RCT & $\begin{array}{l}\text { Unspecified } \\
\text { LH vs. VH }\end{array}$ & 504 & Benign uterine diseases & $\begin{array}{l}\text { Malignancy, } \mathrm{POP}^{\ddagger} \text {, uterine size }> \\
12 \text { week gestation }\end{array}$ & $\begin{array}{l}\text { Operative data, } \\
\text { complications }\end{array}$ & high \\
\hline Ghezzi, 2010 & RCT & TLH vs. VH & 82 & Benign uterine diseases & $\begin{array}{l}\text { Malignancy, } \mathrm{POP}^{\ddagger} \text {, uterine size }> \\
14 \text { week gestation, large adnexal } \\
\text { mass }\end{array}$ & $\begin{array}{l}\text { Operative data, } \\
\text { complications }\end{array}$ & high \\
\hline Hwang, 2002 & $\mathrm{RCT}$ & $\begin{array}{l}\text { LAVH, vs. } \\
\text { TAH vs. VH }\end{array}$ & 60 & Myoma $>8 \mathrm{~cm}$ & $\begin{array}{l}\text { other benign gynecological } \\
\text { conditions except myoma }\end{array}$ & $\begin{array}{l}\text { Operative data, } \\
\text { complications }\end{array}$ & high \\
\hline $\begin{array}{l}\text { Mohammed, } \\
2017\end{array}$ & RCT & LAVH vs. VH & 50 & $\begin{array}{l}\text { Benign uterine diseases, } \\
\text { age }(40-70 \text { years), } \\
\text { estimated uterine } \\
\text { weight }<280 \mathrm{~g}\end{array}$ & $\begin{array}{l}\text { BMI > 30, endometriosis, previous } \\
\text { myomectomy, medical disorder }\end{array}$ & $\begin{array}{l}\text { Operative data, } \\
\text { complications }\end{array}$ & unclear \\
\hline Ottosen, 2000 & $\mathrm{RCT}$ & $\begin{array}{l}\text { LAVH vs. } \\
\text { TAH vs. VH }\end{array}$ & 80 & $\begin{array}{l}\text { Benign uterine disease, } \\
\text { myoma }<15 \mathrm{~cm}\end{array}$ & $\begin{array}{l}\text { Malignancy, uterine size }>16 \\
\text { week gestation, ovarian } \\
\text { pathology, dense pelvic adhesion, } \\
\text { possible VH }\end{array}$ & $\begin{array}{l}\text { Operative data, } \\
\text { complications }\end{array}$ & high \\
\hline Ribeiro, 2003 & RCT & $\begin{array}{l}\text { TAH vs. TLH } \\
\text { vs. VH }\end{array}$ & 40 & Benign uterine diseases & $\begin{array}{l}\text { Estimated uterine volume }>400 \\
\mathrm{~cm}^{3} \text {, medical disorders }\end{array}$ & $\begin{array}{l}\text { Operative data, } \\
\text { complications, } \\
\text { inflammatory } \\
\text { response }\end{array}$ & high \\
\hline Roy, 2011 & RCT & $\begin{array}{l}\text { LAVH vs. } \\
\text { TLH vs. VH }\end{array}$ & 90 & $\begin{array}{l}\text { Benign uterine diseases, } \\
\text { estimated uterine } \\
\text { weight }<400 \mathrm{~g}\end{array}$ & Malignancy, $\mathrm{PID}^{\S}, \mathrm{POP}^{\ddagger}$ & $\begin{array}{l}\text { Operative data, } \\
\text { complications }\end{array}$ & high \\
\hline Soriano, 2001 & $\mathrm{RCT}$ & LAVH vs. VH & 77 & $\begin{array}{l}\text { Estimated uterine size > } \\
280 \mathrm{~g} \text {, contraindications } \\
\text { to } \mathrm{VH}\end{array}$ & Malignancy & $\begin{array}{l}\text { Operative data, } \\
\text { complications }\end{array}$ & high \\
\hline Sesti, 2014 & RCT & $\begin{array}{l}\text { LAVH vs. } \\
\text { TLH vs. VH }\end{array}$ & 108 & $\begin{array}{l}\text { Symptomatic myoma, } \\
\text { age }<55 \text { years, uterine } \\
\text { size }>12 \text { week gestation }\end{array}$ & $\begin{array}{l}\text { Malignancy, nulliparity, uterine } \\
\text { size }>16 \text { week gestation, previous } \\
\text { uterine surgery, }\end{array}$ & $\begin{array}{l}\text { Operative data, } \\
\text { complications }\end{array}$ & low \\
\hline Sesti, 2008 & RCT & $\begin{array}{l}\text { LAVH vs. } \\
\text { TLH vs. VH }\end{array}$ & 100 & $\begin{array}{l}\text { Symptomatic myoma, } \\
\text { age }<55 \text { years, uterine } \\
\text { size }>12 \text { week gestation }\end{array}$ & $\begin{array}{l}\text { Malignancy, nulliparity, uterine } \\
\text { size }>16 \text { week gestation, previous } \\
\text { uterine surgery, }\end{array}$ & $\begin{array}{l}\text { Operative data, } \\
\text { complication }\end{array}$ & unclear \\
\hline Sesti, 2008 & RCT & LAVH vs. VH & 80 & $\begin{array}{l}\text { Symptomatic myoma, } \\
\text { age }<55 \text { years, uterine } \\
\text { size }>12 \text { week gestation }\end{array}$ & $\begin{array}{l}\text { Malignancy, nulliparity, uterine } \\
\text { size }>16 \text { week gestation, previous } \\
\text { uterine surgery, }\end{array}$ & $\begin{array}{l}\text { Operative data, } \\
\text { complication }\end{array}$ & unclear \\
\hline Zhu, 2009 & RCT & LAVH vs. VH & 69 & Benign uterine diseases & Malignancy & $\begin{array}{l}\text { Operative data, } \\
\text { complication }\end{array}$ & high \\
\hline
\end{tabular}




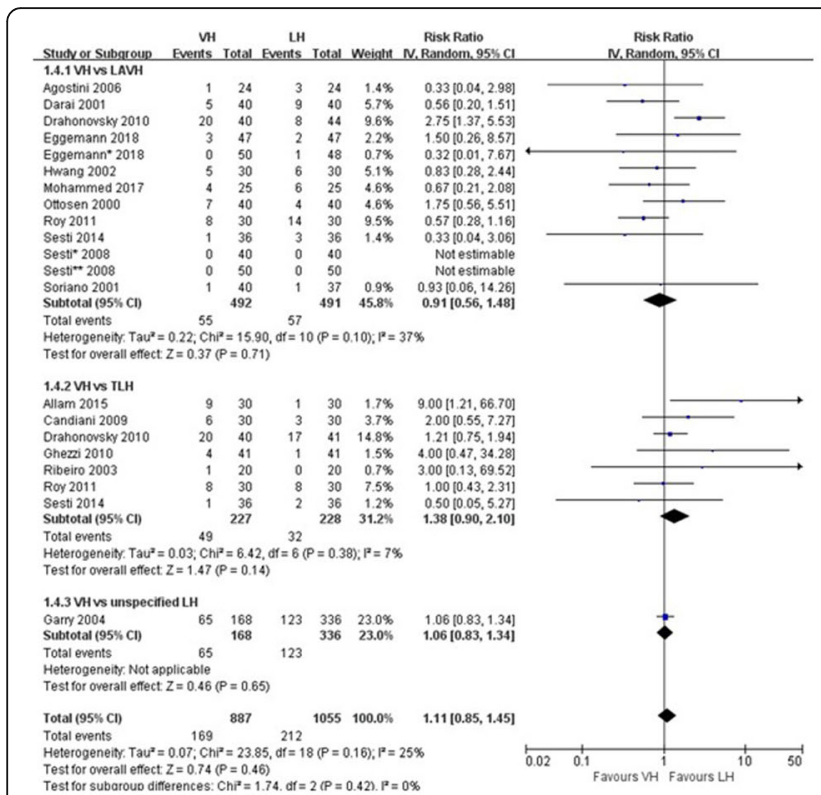

a

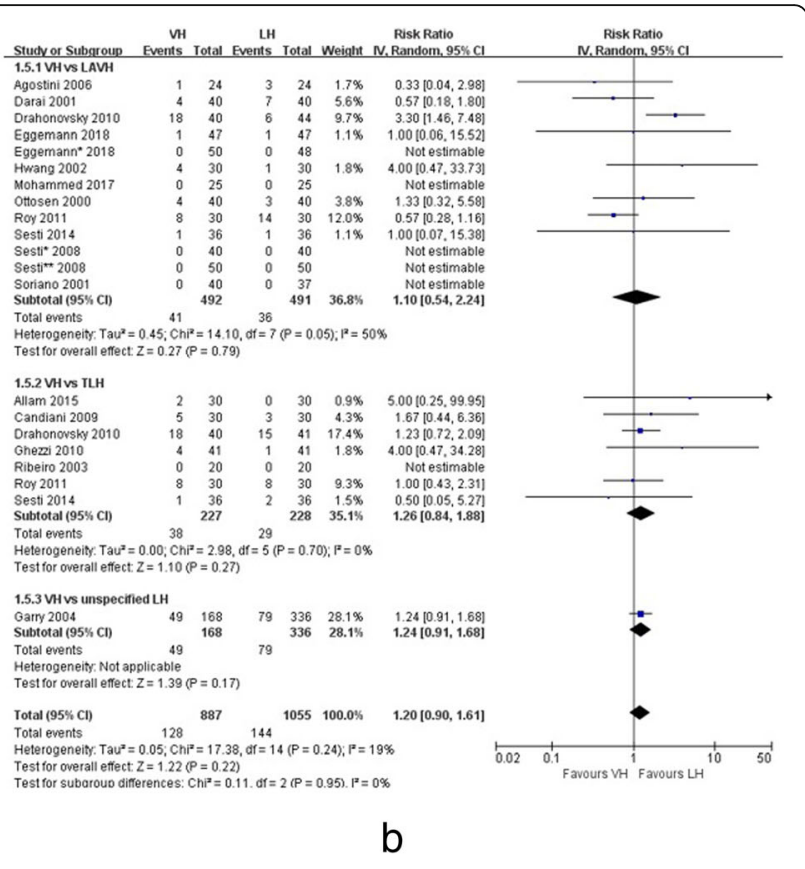

Fig. 3 Forest plots of overall (a) and grade I (b) complications analog scale (VAS) on the day of surgery in four studies $[5,19,27,29]$, at $24 \mathrm{~h}$ after surgery in three studies [5, $17,29]$ and at $48 \mathrm{~h}$ after surgery in three studies $[5,19$, 29]. VH was associated with significantly lower VAS pain scores than LH at $24 \mathrm{~h}$ after surgery (WMD -0.53 , 95\% $\mathrm{CI} ;-0.70$ to $-0.35, p<.0001, \mathrm{I}^{2}=0 \%$ ), with low heterogeneity (Fig. 4). There was no difference between the two groups on the day of surgery (WMD $0.80,95 \% \mathrm{CI}$; -0.08 to $1.68, p=0.07$ ) and at $48 \mathrm{~h}$ after surgery (WMD $-0.20,95 \% \mathrm{CI} ;-0.61$ to $0.22, p=0.35)$. Eleven studies reported on the length of hospital stay [14, 17, 19, 21-28]. There was no difference in the length of hospital stay between VH and LH (WMD - 6.57 h, 95\% CI; - 18.65 to $5.50 \mathrm{~h}, p=0.29)$, and there was high heterogeneity $\left(\mathrm{I}^{2}=\right.$ 99\%). Three studies assessed the duration of recuperation $[14,17,25]$. A difference in the recuperation time between $\mathrm{VH}$ and $\mathrm{LH}$ was not found (WMD 0.65 days, $95 \% \mathrm{CI} ;-6.01$ to 7.30 days, $p=0.85$ ), and there was high heterogeneity $\left(\mathrm{I}^{2}=92 \%\right)$.

\section{Assessment of the quality of evidence}

We used the GRADEpro GTD web-based software to rate the quality of each outcome according to GRADE guidelines, and the results are summarized in Table 3.

\section{Discussion}

The surgical approach of hysterectomy is the most important factor responsible for postoperative morbidity. Many studies have compared the surgical approach and complications according to the type of surgery to determine which method is best for the patient. The conclusion suggests that abdominal hysterectomy is inferior to $\mathrm{VH}$ and LH [32]. There were few randomized trials comparing $\mathrm{VH}$ and $\mathrm{LH}$ for postoperative complications, operative time, hospital stay, and recovery. The results of our metaanalysis showed no difference between the two groups for the overall rate of complications, including grade I, II and III complications of intraoperative blood loss, intraoperative conversion, length of hospital stay and length of recuperation after surgery. $\mathrm{VH}$ was associated with a shorter operative time and less pain at $24 \mathrm{~h}$ after surgery than $\mathrm{LH}$. An important matter of concern about LH is a higher incidence of urinary tract injuries [33]. Our meta-analysis showed no significant difference in urinary tract injuries between VH and LH (10 of 887 vs. 10 of $1055 ; p=0.68$ ). A recent study of 839 women undergoing hysterectomy for benign indications reported that the incidence of urinary tract injuries was $4.3 \%$, including an incidence of $2.9 \%$ for bladder injury and $1.8 \%$ for ureteral injury [34]. One review article reported that the incidence of ureteral injury is estimated to be 0.03 to $2 \%$ for $\mathrm{AH}, 0.02$ to $0.5 \%$ for $\mathrm{VH}$ and 0.2 to $6 \%$ for LH [35]. In this meta-analysis, we found that the incidence of urinary tract injuries was $1.02 \%$. Hence, the incidence of ureteral injury was unlikely to be underreported in the included studies. Interestingly, we found two fistula formations following TLH but no fistula formations following VH. During TLH, many surgeons use electrical laparoscopic instruments to cauterize the uterine artery and dissect the vesicouterine fold; the incidence of fistula formation might thus increase as a consequence of thermal injury [36]. A Cochrane review in 2015 concluded that $\mathrm{VH}$ appears to be superior to $\mathrm{LH}$ for 


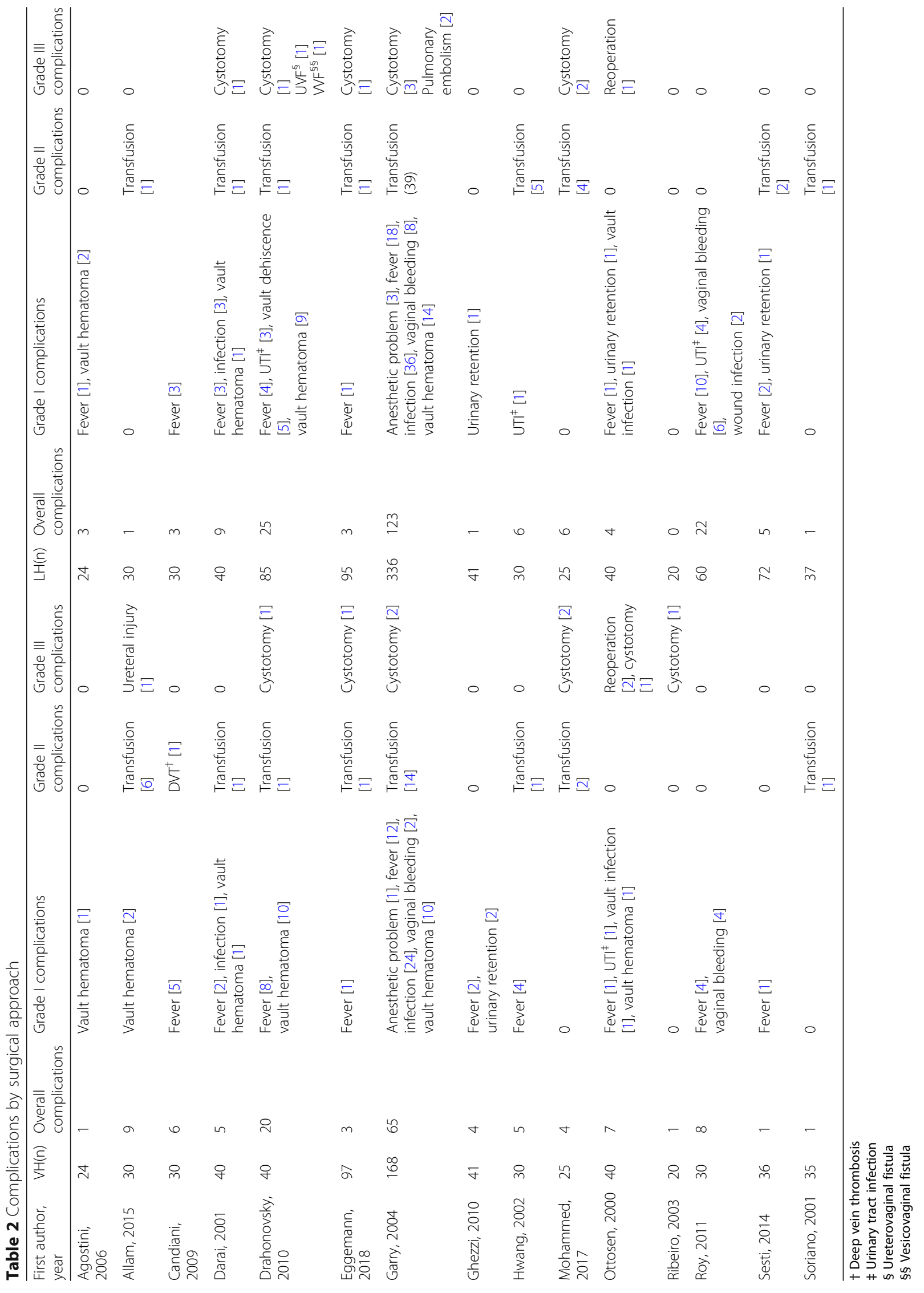




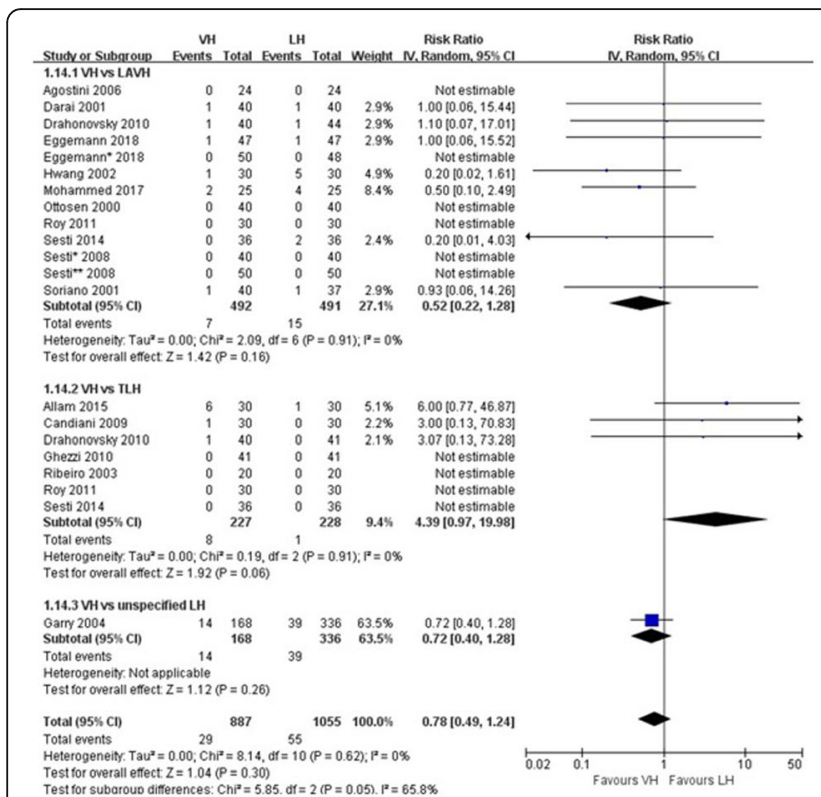

a

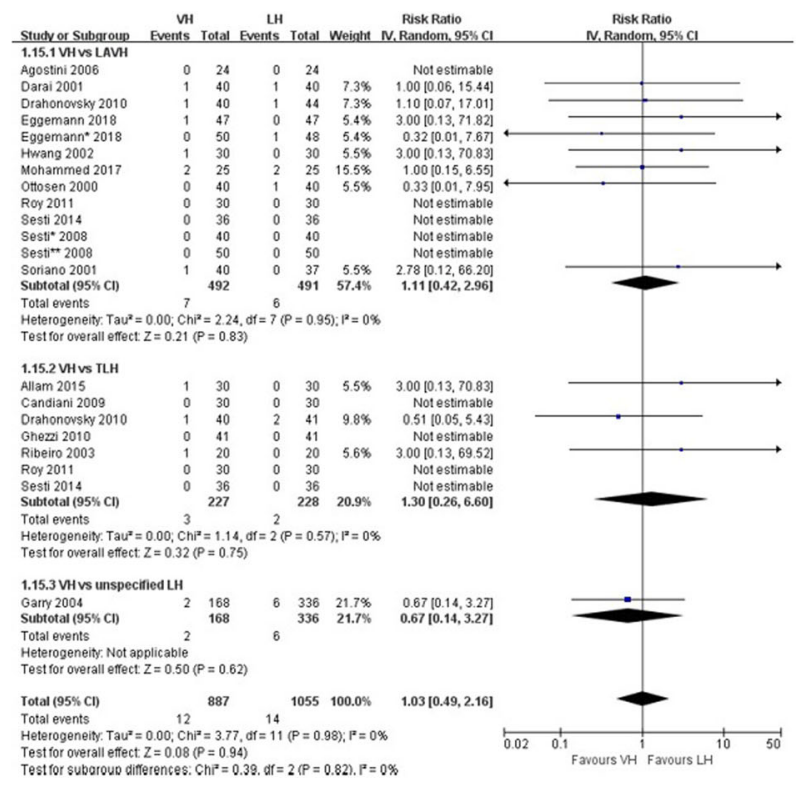

b

Fig. 4 Forest plots of grade II (a) and grade III (b) complications

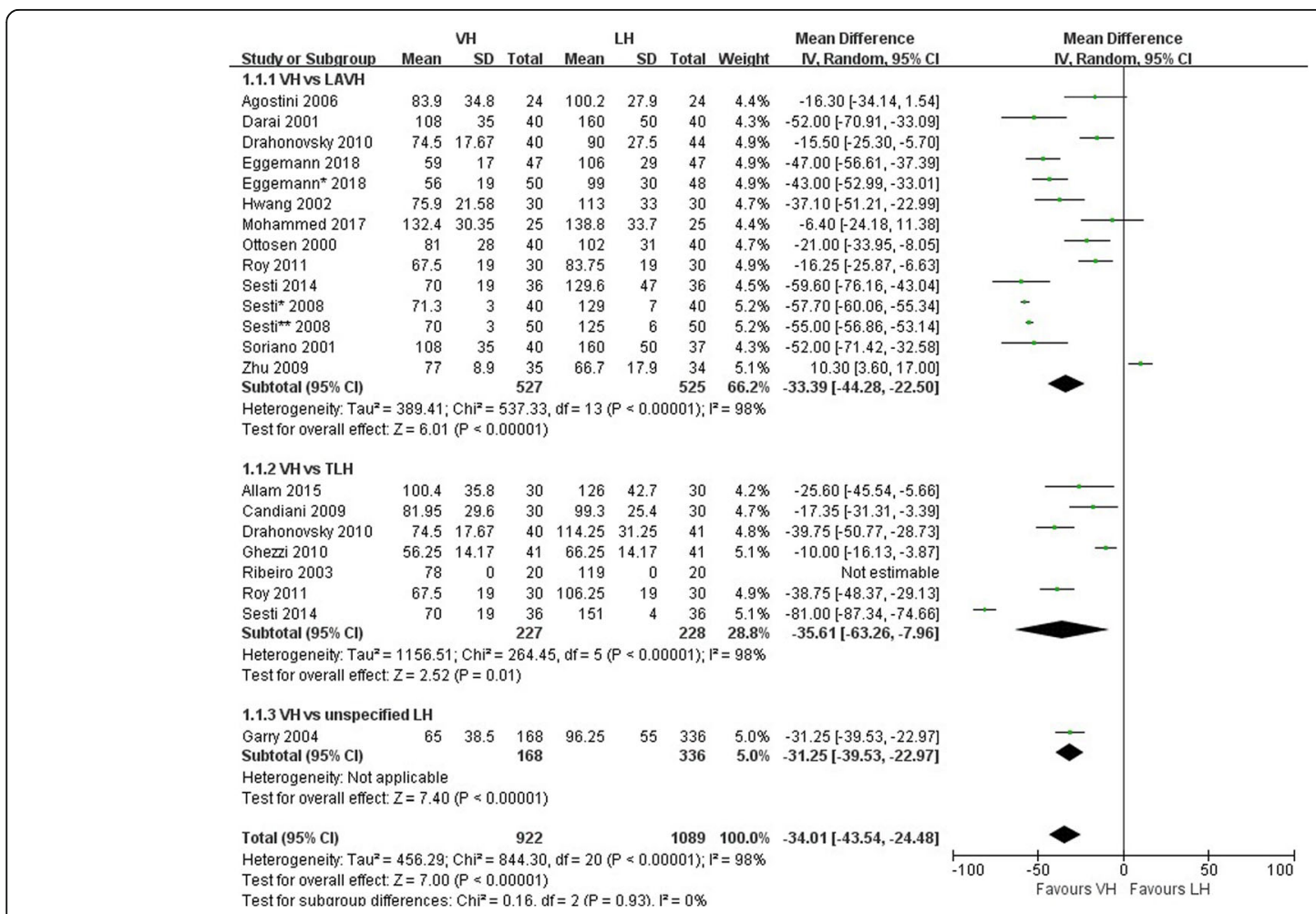

Fig. 5 Forest plot of operating time 


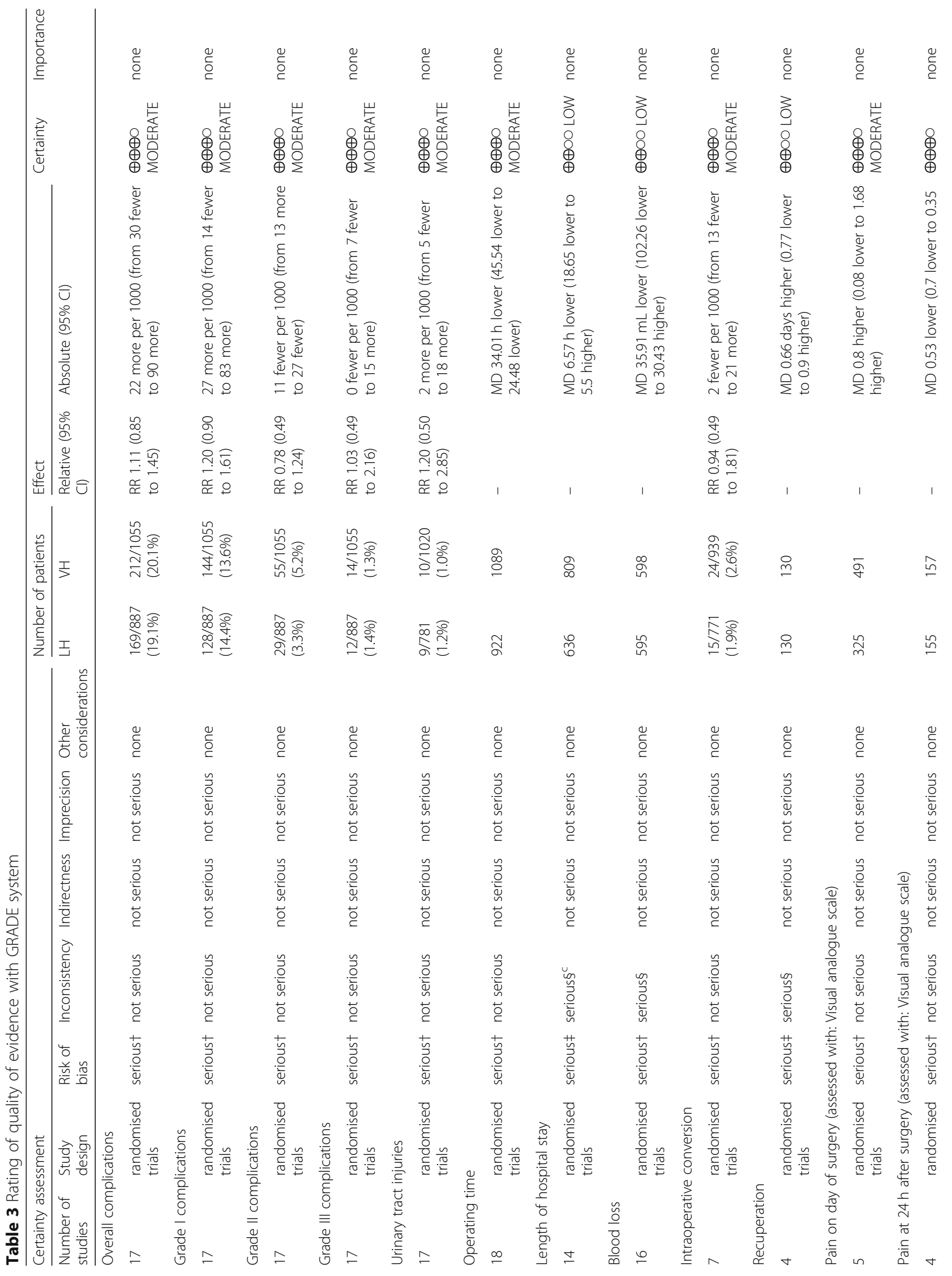




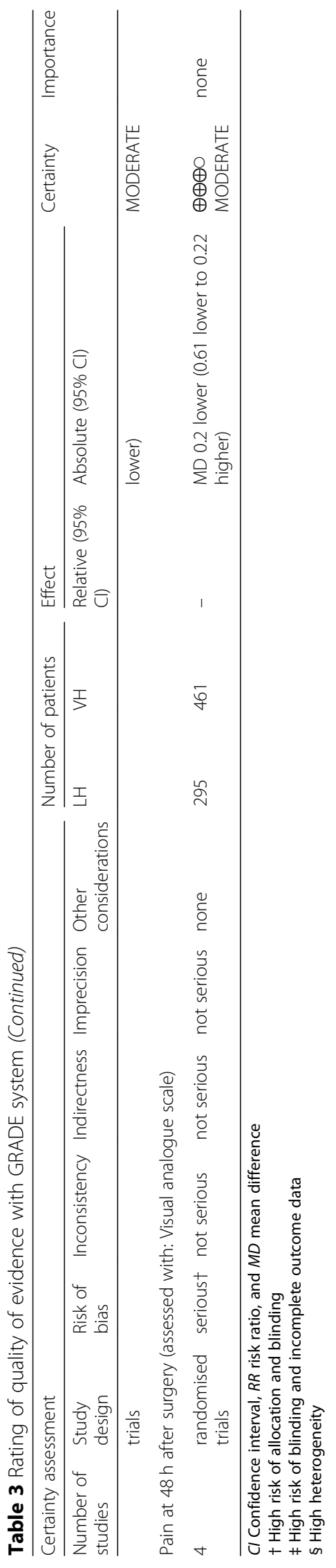


benign indications, as $\mathrm{VH}$ is associated with a faster return to normal activities than $\mathrm{LH}$ according to a meta-analysis including two studies of 140 patients [14, 17], and there were no advantages of $\mathrm{LH}$ over $\mathrm{VH}$, as the operation time was longer for $\mathrm{LH}$ and the incidence of urinary tract injuries was greater for TLH than for $\mathrm{VH}$ [32]. Comparing our meta-analysis including four additional RCTs with 440 patients (VH vs. $\mathrm{LH}$ ) to Cochrane review in 2015, the operation time of $\mathrm{VH}$ was significantly faster than that of $\mathrm{LH}$ similarly but we found no difference between the two groups in the time to return to normal activities, incidence of urinary tract injury and length of hospital stay. Furthermore, $\mathrm{VH}$ was associated with reduced pain scores at $24 \mathrm{~h}$ after surgery. The more postoperative pain in LAVH in our study might be caused by the pneumoperitoneum, the pain caused by traction of uterus and the abdominal incisions for the ports [24]. One study concluded that LH was the least cost-effective due to the expensive laparoscopic devices and long operation time [37]. The operation time of LH has shortened over the last couple decades. However, the cost of disposable laparoscopic devices is inevitably more expensive than that of the conventional surgical instruments used in $\mathrm{VH}$.

Gynaecologists around the world should focus on the effect of the rapid development of LH on the treatment of benign indications, especially $\mathrm{VH}$ training and skills among residents. When deciding the route of hysterectomy, the preference and proficiency of the surgeon may be the most decisive factors. As a result, if LH is performed more often than $\mathrm{VH}$, gynaecologists in the future will be unfamiliar with $\mathrm{VH}$, leading to a more profound decrease in the implementation of VH. Despite evidence supporting benefits of $\mathrm{VH}$, current statistics indicate $\mathrm{VH}$ is underutilised in treating benign gynaecologic conditions [4]. The decreased utilisation of $\mathrm{VH}$ is undesirable because $\mathrm{VH}$ is the least invasive approach, shorter operating time and less cost than other types of hysterectomy from an evidence-based viewpoint. Main causes associated with decreased utilisation of $\mathrm{VH}$ include changes of resident training in surgical techniques due to the tremendous developments of laparoscopic skills and devices, changes of surgical skills in practice, attention to alternative hysterectomy techniques, and enormous propaganda effects of laparoscopic device companies. To increase the rate of $\mathrm{VH}$ as the primary approach in possible cases, teaching hospitals around the world should try to increase utilisation of $\mathrm{VH}$ on purpose for increasing familiarity with $\mathrm{VH}$ during resident training.

According to our review, if both procedures are technically feasible, $\mathrm{VH}$ exhibits advantages in the operating time, which can be one of the most important factors for reducing hospital cost. All of hysterectomy cannot be performed by $\mathrm{VH}$, but all of hysterectomy should not be performed laparoscopically.
The limitation of our study is that all included studies had a high risk of bias in blinding despite the RCT design. Hence, no outcome had high-quality evidence according to the GRADE methodology. However, given that our primary outcome was the comparison of complication risk between the two groups, outcomes such as overall complications, grade 3 complications and risk of urinary tract injuries had moderate-quality evidence. Additional largescale, multicenter, long-term randomized trials including objective outcome assessment will be required to definitively establish the value of $\mathrm{LH}$ vs $\mathrm{VH}$.

\section{Conclusion}

The results of this study suggest that VH should be the treatment of benign gynecologic disease when both operative methods are available. Large randomized controlled trials should be performed to identify differences in $\mathrm{VH}$ and $\mathrm{LH}$ outcomes for operation time, postoperative pain, perioperative complications and cost.

\section{Additional file}

Additional file 1: The raw data of the enrolled studies. (XLSX $12 \mathrm{~kb}$ )

\begin{abstract}
Abbreviations
AH: Abdominal hysterectomy; Cl: Confidence interval; LAVH: Laparoscopicassisted vaginal hysterectomy; LH: Laparoscopic hysterectomy; RCTs: Randomised controlled trials; RRs: Risk ratios; TLH: Total laparoscopic hysterectomy; VH: Vaginal hysterectomy; WMDs: Weighted mean differences
\end{abstract}

\section{Acknowledgements}

Not applicable.

\section{Authors' contributions}

Substantial contributions to conception and design; JWB, Authors who participated in drafting the article or revising it critically for important intellectual content; JWB, SRO, SHL, Authors who participated in selection of studies and analysis and interpretation of data; SRO, SHL, Author who gave final approval of the version to be submitted and any revised version; JWB, Authors who participated in data extraction; SRO, SHL, SJK, Authors who participated in resolving all conflicts in data extraction and management; SHL, SRO, YJC, MSH, JWP, HYK, SJK, JHY, SYC, JSC, JWB

\section{Funding}

The study was funded by DONG-A university. The funding source had no role in study design, data collection, data analysis, data interpretation or preparing manuscript.

\section{Availability of data and materials}

All data generated or analysed during this study are included in this published article and its Additional file 1.

Ethics approval and consent to participate

Not applicable because this study is a review article and a meta-analysis.

Consent for publication

Not applicable because this study is a review article and a meta-analysis.

Competing interests

The authors declare that they have no competing interests. 


\section{Author details}

'Department of Obstetrics and Gynaecology, College of Medicine, Dong-A University, Busan, 26 Daesingongwon-Ro Seo-Gu, Busan 602-812, Republic of Korea. ${ }^{2}$ Department of Obstetrics and Gynaecology, College of Medicine, Hanyang University, Seoul, Republic of Korea.

Received: 20 March 2019 Accepted: 16 June 2019

Published online: 24 June 2019

\section{References}

1. Whiteman MK, Hillis SD, Jamieson DJ, Morrow B, Podgornik MN, Brett KM, et al. Inpatient hysterectomy surveillance in the United States, 2000-2004. Am J Obstet Gynecol. 2008;198(1):34 e1-7.

2. Nieboer TE, Johnson N, Lethaby A, Tavender E, Curr E, Garry R, et al. Surgical approach to hysterectomy for benign gynaecological disease. Cochrane Database Syst Rev. 2009;8(3):CD003677.

3. Driessen SR, Van Zwet EW, Haazebroek P, Sandberg EM, Blikkendaal MD, Twijnstra AR, et al. A dynamic quality assessment tool for laparoscopic hysterectomy to measure surgical outcomes. Am J Obstet Gynecol. 2016; 215(6):754 e1-8.

4. Moen MD, Richter HE. Vaginal hysterectomy: past, present, and future. Int Urogynecol J. 2014;25(9):1161-5.

5. Candiani M, Izzo S, Bulfoni A, Riparini J, Ronzoni S, Marconi A. Laparoscopic vs vaginal hysterectomy for benign pathology. Am J Obstet Gynecol. 2009;200(4):368 e1-7.

6. Clavien PA, Barkun J, de Oliveira ML, Vauthey JN, Dindo D, Schulick RD, et al. The Clavien-Dindo classification of surgical complications: five-year experience. Ann Surg. 2009;250(2):187-96.

7. Liberati A, Altman DG, Tetzlaff J, Mulrow C, Gotzsche PC, loannidis JP, et al The PRISMA statement for reporting systematic reviews and meta-analyses of studies that evaluate healthcare interventions: explanation and elaboration. BMJ. 2009;339:b2700.

8. Moher D, Liberati A, Tetzlaff J, Altman DG. Preferred reporting items for systematic reviews and meta-analyses: the PRISMA statement. Ann Intern Med. 2009:151(4):264-9 W64.

9. Hozo SP, Djulbegovic B, Hozo I. Estimating the mean and variance from the median, range, and the size of a sample. BMC Med Res Methodol. 2005:5:13.

10. Green S, Higgins J. Cochrane handbook for systematic reviews of interventions. Version; 2005.

11. Balshem $H$, Helfand $M$, Schunemann HJ, Oxman AD, Kunz R, Brozek J, et al. GRADE guidelines: 3. Rating the quality of evidence. J Clin Epidemiol. 2011;64(4):401-6.

12. Guyatt G, Oxman AD, Akl EA, Kunz R, Vist G, Brozek J, et al. GRADE guidelines: 1. Introduction-GRADE evidence profiles and summary of findings tables. J Clin Epidemiol. 2011;64(4):383-94.

13. Guyatt GH, Oxman AD, Kunz R, Atkins D, Brozek J, Vist G, et al. GRADE guidelines: 2. Framing the question and deciding on important outcomes. J Clin Epidemiol. 2011;64(4):395-400.

14. Ottosen C, Lingman G, Ottosen L. Three methods for hysterectomy: a randomised, prospective study of short term outcome. BJOG. 2000; 107(11):1380-5

15. Darai E, Soriano D, Kimata P, Laplace C, Lecuru F. Vaginal hysterectomy for enlarged uteri, with or without laparoscopic assistance: randomized study. Obstet Gynecol. 2001:97(5 Pt 1):712-6.

16. Soriano D, Goldstein A, Lecuru F, Darai E. Recovery from vaginal hysterectomy compared with laparoscopy-assisted vaginal hysterectomy: a prospective, randomized, multicenter study. Acta Obstet Gynecol Scand. 2001:80(4):337-41.

17. Hwang JL, Seow KM, Tsai YL, Huang LW, Hsieh BC, Lee C. Comparative study of vaginal, laparoscopically assisted vaginal and abdominal hysterectomies for uterine myoma larger than $6 \mathrm{~cm}$ in diameter or uterus weighing at least $450 \mathrm{~g}$ : a prospective randomized study. Acta Obstet Gynecol Scand. 2002;81(12):1132-8.

18. Ribeiro SC, Ribeiro RM, Santos NC, Pinotti JA. A randomized study of total abdominal, vaginal and laparoscopic hysterectomy. Int J Gynaecol Obstet. 2003;83(1):37-43.

19. Garry R, Fountain J, Brown J, Manca A, Mason S, Sculpher M, et al. EVALUATE hysterectomy trial: a multicentre randomised trial comparing abdominal, vaginal and laparoscopic methods of hysterectomy. Health Technol Assess. 2004;8(26):1-154.
20. Agostini A, Vejux N, Bretelle F, Collette E, De Lapparent T, Cravello L, et al. Value of laparoscopic assistance for vaginal hysterectomy with prophylactic bilateral oophorectomy. Am J Obstet Gynecol. 2006;194(2):351-4.

21. Sesti F, Calonzi F, Ruggeri V, Pietropolli A, Piccione E. A comparison of vaginal, laparoscopic-assisted vaginal, and minilaparotomy hysterectomies for enlarged myomatous uteri. Int J Gynaecol Obstet. 2008;103(3):227-31.

22. Sesti F, Ruggeri V, Pietropolli A, Piccione E. Laparoscopically assisted vaginal hysterectomy versus vaginal hysterectomy for enlarged uterus. JSLS. 2008;12(3):246-51.

23. Drahonovsky J, Haakova L, Otcenasek M, Krofta L, Kucera E, Feyereisl J. A prospective randomized comparison of vaginal hysterectomy, laparoscopically assisted vaginal hysterectomy, and total laparoscopic hysterectomy in women with benign uterine disease. Eur J Obstet Gynecol Reprod Biol. 2010;148(2):172-6

24. Ghezzi F, Uccella S, Cromi A, Siesto G, Serati M, Bogani G, et al. Postoperative pain after laparoscopic and vaginal hysterectomy for benign gynecologic disease: a randomized trial. Am J Obstet Gynecol. 2010;203(2):118 e1-8.

25. Roy KK, Goyal M, Singla S, Sharma JB, Malhotra N, Kumar S. A prospective randomised study of total laparoscopic hysterectomy, laparoscopically assisted vaginal hysterectomy and non-descent vaginal hysterectomy for the treatment of benign diseases of the uterus. Arch Gynecol Obstet. 2011;284(4):907-12.

26. Sesti F, Cosi V, Calonzi F, Ruggeri V, Pietropolli A, Di Francesco L, et al. Randomized comparison of total laparoscopic, laparoscopically assisted vaginal and vaginal hysterectomies for myomatous uteri. Arch Gynecol Obstet. 2014;290(3):485-91.

27. Allam IS, Makled AK, Gomaa IA, El Bishry GM, Bayoumy HA, Ali DF. Total laparoscopic hysterectomy, vaginal hysterectomy and total abdomina hysterectomy using electrosurgical bipolar vessel sealing technique: a randomized controlled trial. Arch Gynecol Obstet. 2015;291(6):1341-5.

28. Mohammed WE, Salama F, Tharwat A, Mohamed I, ElMaraghy A. Vaginal hysterectomy versus laparoscopically assisted vaginal hysterectomy for large uteri between 280 and $700 \mathrm{~g}$ : a randomized controlled trial. Arch Gynecol Obstet. 2017:296(1):77-83.

29. Eggemann $H$, Ignatov A, Frauchiger-Heuer H, Amse T, Costa SD. Laparoscopic-assisted vaginal hysterectomy versus vaginal hysterectomy for benign uterine diseases: a prospective, randomized, multicenter, doubleblind trial (LAVA). Arch Gynecol Obstet. 2018;297(2):479-85.

30. Garry R, Fountain J, Mason S, Hawe J, Napp V, Abbott J, et al. The eVALuate study: two parallel randomised trials, one comparing laparoscopic with abdominal hysterectomy, the other comparing laparoscopic with vaginal hysterectomy. BMJ. 2004;328(7432):129.

31. Zhu L, Lang JH, Liu CY, Shi HH, Sun ZJ, Fan R. Clinical assessment for three routes of hysterectomy. Chin Med J. 2009;122(4):377-80.

32. Aarts JW, Nieboer TE, Johnson N, Tavender E, Garry R, Mol BW, et al. Surgical approach to hysterectomy for benign gynaecological disease. Cochrane Database Syst Rev. 2015;12(8):CD003677.

33. Forsgren C, Altman D. Risk of pelvic organ fistula in patients undergoing hysterectomy. Curr Opin Obstet Gynecol. 2010;22(5):404-7.

34. Ibeanu OA, Chesson RR, Echols KT, Nieves M, Busangu F, Nolan TE. Urinary tract injury during hysterectomy based on universal cystoscopy. Obstet Gynecol. 2009;113(1):6-10.

35. Ugurlu EN. Ureteric Injuries during Laparoscopic Gynecological Operations. World Journal of Laparoscopic Surgery with DVD. 2010;3(3):123-5 \%@ 0974-8938.

36. Adelman MR, Bardsley TR, Sharp HT. Urinary tract injuries in laparoscopic hysterectomy: a systematic review. J Minim Invasive Gynecol. 2014;21(4):558-66.

37. Pynna K, Vuorela P, Lodenius L, Paavonen J, Roine RP, Rasanen P. Costeffectiveness of hysterectomy for benign gynecological conditions: a systematic review. Acta Obstet Gynecol Scand. 2014;93(3):225-32.

\section{Publisher's Note}

Springer Nature remains neutral with regard to jurisdictional claims in published maps and institutional affiliations. 